Landslides (2019) 16:201-211 DOI 10.1007/s10346-018-01133-z Received: 28 December 2018 Accepted: 28 December 2018 Published online: 1 February 2019 (c) Springer-Verlag GmbH Germany part of Springer Nature 2019

\section{Kyoji Sassa \\ The Fifth World Landslide Forum and the final draft of the Kyoto 2020 Commitment}

Progress of the Fifth World Landslide Forum 2020 and the Kyoto 2020 Commitment for global promotion of understanding and reducing landslide disaster risk is reported in this editorial and also in the News/Kyoto Commitment of this issue following a series of report of WLF5 (Sassa (2017a) in Landslides 14 (3), Sassa (2017b) in Landslides 14 (4), Sassa (2017c) in Landslides 14 (5), Sassa $(2018 \mathrm{a}, \mathrm{c})$ in Landslides 15 (3)).

The Fifth World Landslide Forum, November 2-6, 2020, Kyoto, Japan

Implementing and monitoring the ISDR-ICL Sendai Partnerships 2015-2025 - voluntary contribution to the Sendai Framework 2015-2030 and the Agenda 2030-Sustainable Development Goals

Date: 2-6 November 2020

Venue: Kyoto International Conference Center, Kyoto, Japan

Organizers:

International Consortium on Landslides (ICL)

Global Promotion Committee of International Programme on Landslides (GPC/IPL), including the following: United Nations Educational, Scientific and Cultural Organization (UNESCO), World Meteorological Organization (WMO), Food and Agriculture Organization (FAO), United Nations Office for Disaster Risk Reduction (UNISDR), United Nations University (UNU), International Science Council (ISC), World Federation of Engineering Organizations (WFEO), International Union of Geological Sciences (IUGS), International Union of Geodesy and Geophysics (IUGG).

Kyoto University (KU), Japan Landslide Society (JLS), Japanese Geotechnical Society (JGS), Japan Society for Natural Disaster Science (JSNDS)

Organizing Committee Chairs:

Kyoji Sassa (Professor Emeritus, Kyoto University, Secretary General of ICL)

Peter Bobrowsky (Geological Survey of Canada, President of ICL)

Kaoru Takara (Kyoto University, Japan, Executive Director of ICL)

Local Organizing Committee Chairs:

Kaoru Takara (President of the Japanese Society of Natural Disaster Science)

Daisuke Higaki (Chair of ICL Committee of the Japan Landslide Society)

Ikuo Towhata (Former President of the Japanese Geotechnical Society)

Secretary Generals:

Ryosuke Uzuoka (Professor of the Disaster Prevention Research Institute, Kyoto University, Japan)
Kazuo Konagai (Professor Emeritus, University of Tokyo, Principal researcher of ICL Headquarters)

Khang Dang (Research Promotion Officer of ICL)

\section{Invitation to the Fifth World Landslide Forum}

The International Consortium on Landslides (ICL) and the Global Promotion Committee of the International Programme on Landslides (GPC/IPL) invite you to join the 5th World Landslide Forum (WLF5) on November 2-6, 2020, in Kyoto, Japan. This forum will be the opportunity for a mid-term review of the ISDR-ICL Sendai Partnerships 2015-2025-a voluntary contribution to the Sendai Framework 2015-2030 and the Agenda 2030-Sustainable Development Goals, especially Goal 11 Make cities and human settlements inclusive, safe, resilient and sustainable (Sassa 2017d). Participants of the 4 th World Landslide Forum adopted the 2017 Ljubljana Declaration on Landslide Risk Reduction-Contributing to the Sendai Framework for Disaster Risk Reduction. The declaration proposed the concept of the Kyoto 2020 Commitment for Global Promotion of Understanding and Reducing Landslide Disaster Risk (KC2O2O) to develop the ISDR-ICL Sendai Partnerships 2015-2025 to a medium and long-term global alliance that will accelerate and incentivize action for landslide risk reduction. The organization of $\mathrm{WLF}_{5}$ and the draft of the $\mathrm{KC}_{2} \mathrm{O}_{2} \mathrm{O}$ have significantly progressed through the 2017 ICL-IPL UNESCO Conference at UNESCO from 29 November to 1 December in 2017 and 2018 ICL-IPL Kyoto Conference on 1-4 December 2018. WLF5 organizers invite everyone to join $\mathrm{WLF}_{5}$ and also the $\mathrm{KC}_{2020}$. The updated outline of WLF5 and the list of invited speakers who were invited by each session coordinator and accepted by 15 December 2018 are reported below and also included in the News/Kyoto Commitment of this issue (Sassa et al. 2019).

\section{Themes of WLF 5}

Theme 1: Sendai Partnerships 2015-2025 and the Kyoto 2020 Commitment

Theme 2: Hazard and vulnerability mapping and zonation

Theme 3: Monitoring and early warning

Theme 4: Testing, modeling, and risk assessment

Theme 5: Education and capacity development for risk management and risk governance

Theme 6: Catastrophic landslides: causes and consequences Theme 7: Frontiers of landslide science and innovative practices 
Theme 8: Specific topics other than themes 1-7 (proposed by active groups)

The 5th of November was designated as "World Tsunami Awareness Day (WTAD)" by 7oth session of the UN General Assembly 2015. It recognizes landslides near a coastline or at the bottom of the ocean as one among the major causes of tsunami. Symposia and sessions on landslide-induced tsunamis will be organized on 4 and 5 November 2020 as a part of WLF5. A new Intergovernmental Panel on landslide-induced tsunamis, floods, and flows has been proposed to discuss the subject in the meeting on 4 or 5 November 2020 within the WLF5 venue.

\section{Publication of WLF5}

Three types of publication are planned.

1. Thematic issue for WLF5 Landslides vol. 17 (10)

Free access from 10 October to 10 November 2020. Papers are submitted to editorial manager for Landslides https://www.editorialmanager.com/lasl/default.aspx

The review process for papers submitted in this issue is exactly the same as for the regular papers. However, the authors of the accepted papers are invited to the $\mathrm{WLF}_{5}$ as "Invited lecturer or Keynote lecturer in an appropriate session." Submission of papers for the thematic issue is open from October 2018.
2. Full color books under the above eight themes (similar to the full color books for WLF1-WLF4)

Papers for these proceedings are submitted into the editorial manager for WLF5 which will be open from 1 April 2019. The submitted papers will be peerreviewed and finally edited by the editors of WLF5, which will further be checked and edited and/or formatted by the publisher to match with the format of the forum full color book proceedings.

3. CD proceedings

Type A. Papers/abstract/PPT submitted to the CD session coordinators.

It will take a shorter period from submission to publication in $\mathrm{CD}$ proceedings.

Type B. Papers under the eight themes which are not included due to deadline of publication of full color books, but accepted by the coordinator of one of the eight themes. Those papers will also be included in the CD book of WLF5.

\section{Schedule of $\mathrm{WLF}_{5}$ organization}

The organization schedule is summarized in the table. This table is published in "WLF5 outline" at the end of each issue of Landslides. The date and the content of this table are periodically updated while the preparation of WLF5 progresses.

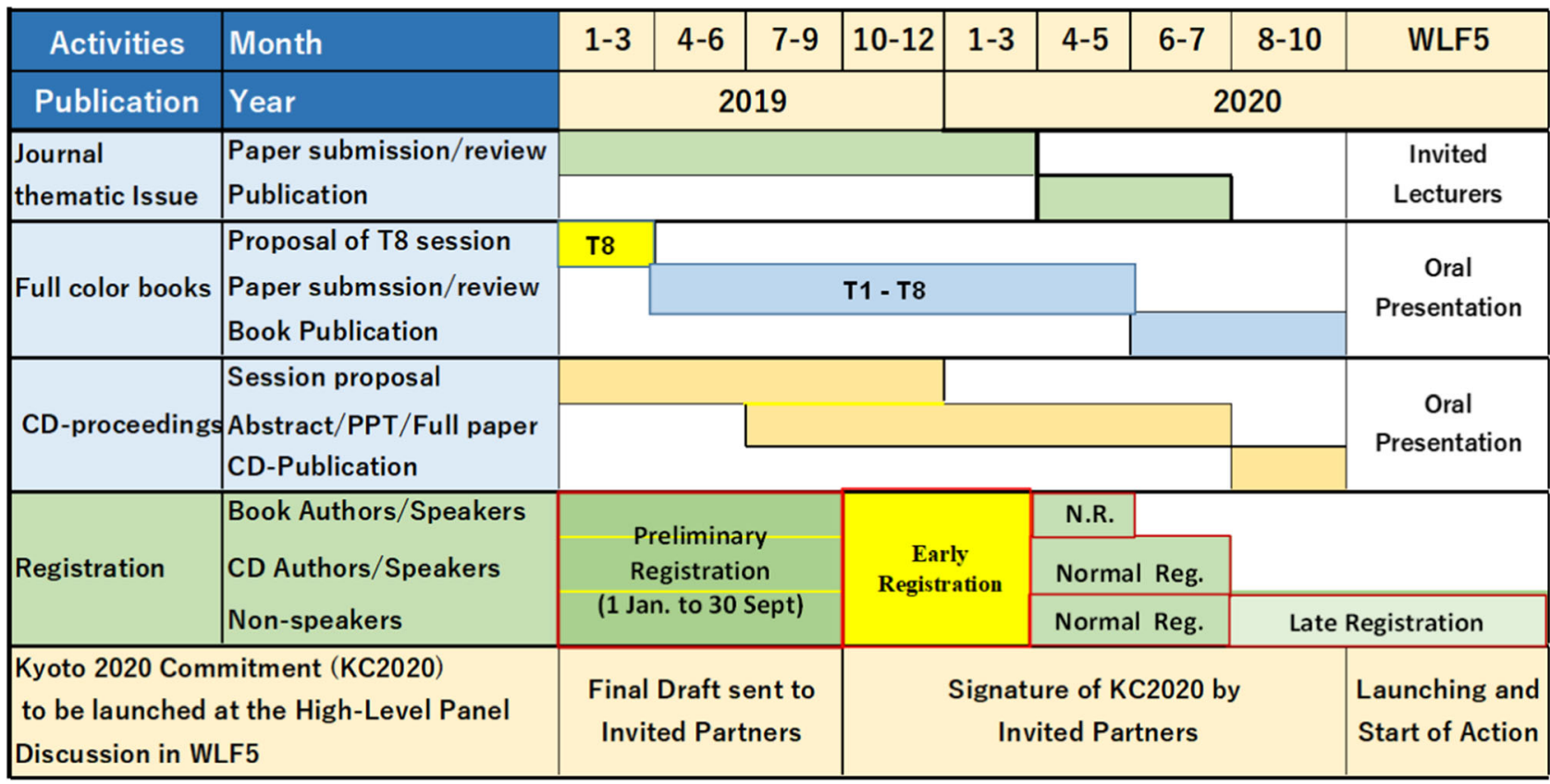


1. Submission of papers to the thematic issue is accepted by the end of March 2020. Accepted papers will be published online first in the webpage of Landslides, and then published in the vol.17, No. 10 as the WLF5 thematic issue of Landslides in October 2020.

2. Papers submitted to the full color book proceedings are accepted from 1 April 2018 to the end of May 2020. Editors managing the review and publication process are the editors of the WLF5 book proceedings.

3. Papers or abstract or PPT submitted for the WLF 5 CD proceedings are accepted until the end of July 2020, which is the deadline for the submission of digital proceeding of each session to the WLF5 secretariat. The secretariat will combine all session proceedings to one WLF5 CD proceedings book with ISBN number. Editors managing review of this proceedings book are the editors of each $\mathrm{CD}$ session.>

\section{Preliminary registration of $\mathrm{WLF}_{5}$ for speakers and exhibitors/ sponsors}

Preliminary registration web is open for speakers and exhibitors/ sponsors within WLF5 webpage <http://wlf5.iplhq.org/preliminary-registration/>.

Objectives and benefits of preliminary registration

1) The information of the themes selected by the Preliminary Registered Speakers (PRS) and a tentative title are useful for the theme coordinators as well as WLF5 secretariat for managing the sessions.

2) There is no abstract submission stage in WLF5 such as the one used in WLF4. Theme coordinators/WLF5 secretariat will communicate with PRS on his/her presentation contents directly.

3) All updated and detailed information of $\mathrm{WLF}_{5}$ will be sent to PRS directly.

4) PRS from developing countries who need financial support to participate in the $\mathrm{WLF}_{5}$ are notified to the $\mathrm{WLF}_{5}$ secretariat to plan for possible travel support.

5) The forum registration fee for the PRS will be reduced by 1000 JPY from the actual registration fee.

6) Exhibitors and sponsors may have specific request pertinent to the exhibition/sponsorship logistics. WLF5 secretary will consult with the Preliminary Registered Exhibitors/Sponsors (PRES) regarding those details.>

Sponsors supporting participants from developing countries and young scientists are called through this announcement. Types of sponsorship will be 500,000 JPY; 300,000 JPY;
100,000 JPY; and more than one unit of 10,000 JPY. Benefits of sponsors and exhibitors include recognition, advertisements, and technical introduction in WLF5 webpage/full color books/Landslide Journal/booths and posters, and free nonspeaker tickets.

Potential exhibitors and sponsors are requested to complete preliminary registration through the WLF5 webpage. The WLF5 secretariat will consult with the PRES regarding the details.

Kyoto 2020 Commitment (KC2020)

The concept of the Kyoto 2020 Commitment was approved by the 2017 Ljubljana Declaration (Sassa 2017b); the zero-draft of KC2020 was made during the 2017 ICL-IPL UNESCO Conference (Sassa 2018a). The zero-draft was continuously revised throughout 2018 to revise it to the final draft which was approved by 2018 ICL-IPL Kyoto Conference on 1-4 December 2018.

The International Consortium on Landslides (ICL) and the Global Promotion Committee of IPL (International Programme on Landslides) as well as the ISDR-ICL Sendai Partnerships 20152025 cordially invite a wide range of parties to join the initiative to launch this planned commitment at WLF5.

Invited parties are ICL members (ICL full members, ICL associates, and ICL supporters), ICL supporting organizations, partners of the Sendai Partnerships 2015-2025, and governments which support ICL members in their countries. New ICL members and new ICL supporting organizations are also called to join the $\mathrm{KC} 2 \mathrm{O} 2 \mathrm{O}$.

We will send the invitation letter along with the document of $\mathrm{KC}_{2} \mathrm{O} 20$ to potential partners from January 2019. We will invite agreed partners to the 2019 ICL-IPL UNESCO Conference on 16-19 September 2019. When potential parties will agree, the first group of partners will sign the $\mathrm{KC} 2 \mathrm{O} 2 \mathrm{O}$ document. All partners are expected to finish signing it by 2 November 2020 .

The $\mathrm{KC} 2 \mathrm{O} 2 \mathrm{O}$ is a commitment to the 2030 Agenda Sustainable Development Goals, the New Urban Agenda, and the Paris Climate Agreement as well as the ISDR-ICL Sendai Partnerships 2015-2025 and the Sendai Framework for Disaster Risk Reduction 2015-2030. It will be expected to be established in the high-level panel discussion for the Kyoto 2020 Commitment on 3 November 2020 in the Kyoto International Conference Center (KICC). Panelists are expected from the wide range of landslide community including ICL members, United Nations organizations, governmental organizations, intergovernmental and international organizations, academia (universities and institutes), companies and other private sectors, and active young individuals working on landslide risk reduction, which shall effectively contribute to $\mathrm{WLF}_{5}$ and the further development of the $\mathrm{KC} 2 \mathrm{O} 2 \mathrm{O}$. 


\section{Final Draft}

\section{Kyoto 2020 Commitment for Global Promotion of Understanding and Reducing Landslide Disaster Risk \\ A Commitment to the ISDR-ICL Sendai Partnerships 2015-2025, the Sendai Framework for Disaster Risk Reduction 2015- 2030, the 2030 Agenda Sustainable Development Goals, the New Urban Agenda and the Paris Climate Agreement}

\section{Preamble}

Landslide disasters are the result of impacts of hazardous movement of soil and rocks that threaten vulnerable human settlements and infrastructure in mountains, cities, on coasts, and islands. An increase in the frequency and/or magnitude of heavy rainfall and shifts in the location, timing and periodicity of rainfall and permafrost/glacier degradation due to changing climate and global warming may significantly intensify the risk of landslides in many landslide prone areas.

Developments in mountains and coastal areas, including infrastructure construction such as roads, railways, energy and communication corridors, expansion of urban areas, including deforestation due to population growth and movement increase exposure to the hazards of landslides. Landslide disaster risk reduction is a globally important objective in all countries/regions where people living near mountains and on slopes are exposed to landslides.

The International Consortium on Landslides (ICL) proposed the 'ISDR-ICL Sendai Partnerships 2015-2025 for Global Promotion of Understanding and Reducing Landslide Disaster Risk' in the Working Session "Underlying Risk Factors" during the 3rd World Conference on Disaster Risk Reduction (WCDRR) in Sendai, Japan, 2015. The Sendai Partnerships was adopted and signed by 17 United Nations, international and national stakeholders. Joint efforts thereafter have been made and resulted in significant outcomes and materials including the edition and publication of the open access full color book "ISDR-ICL Sendai Partnerships 2015-2025", Vol. 1 of the Fourth World Landslide Forum (Ljubljana, 2017), the edition of "Landslide Dynamics: ISDR-ICL Landslide Interactive Teaching Tools", as well as the enhanced publication of the monthly full-color journal Landslides: Journal of the International Consortium on Landslides.

The landslide risk to human settlements in mountainous and coastal areas in many countries will likely continue to rise including after the latter-half period of the Sendai Partnerships 2015-2025. In September 2015, the United Nations General Assembly adopted the 2030 Agenda for Sustainable Development and its 17 Sustainable Development Goals (SDG) including SDG 11 'Make cities and human settlements inclusive, safe, resilient and sustainable' and SDG 13 'Take urgent action to combat climate change and its impacts'. As a voluntary commitment to the 2030 Agenda, to the Sendai Framework for Disaster Risk Reduction 2015-2030 and to the Paris Agreement on Climate Change as well as to the ISDR-ICL Sendai Partnerships itself, participants in the Fourth World Landslide Forum considered and further endorsed the first outline of a commitment, the Kyoto 2020 Commitment, as a stable framework to mobilize in the medium and long term a global alliance which will accelerate and incentivize action for landslide disaster risk reduction.

The High-Level panel discussion on "Strengthening Intergovernmental Network and the International Programme on Landslides (IPL) for ISDR-ICL Sendai Partnerships 2015-2025 for global promotion of understanding and reducing landslide disaster risk" was organized during the Fourth World Landslide Forum. The panelists were from the signatory organizations of Sendai Partnerships (ICL, UNESCO, WMO, FAO, UNU, ICSU, WFEO, IUGS, IUGG, Cabinet Office of Japan, Italian Civil Protection, Global Risk Forum, Davos) and new signatory organizations (the Indonesian National Agency for Disaster Management, the Administration of the Republic of Slovenia for Civil Protection and Disaster Relief, Ministry of Natural Resources and Environment, Vietnam, IRDR Science Committee, EuroGeoSurveys) as well as experts in this field.

The outcome of this High-Level panel discussion was reviewed by the Round Table Discussion to promote the Sendai Partnerships and the participants approved the 2017 Ljubljana Declaration on Landslide Risk Reduction. The Declaration endorsed the plan for the organization of the Fifth World Landslide Forum in Kyoto, Japan in November 2020 and the preparation of the Kyoto 2020 Commitment of a global alliance which aims, in the medium and long term, to accelerate and incentivize action for landslide disaster risk reduction to 2025,2030 and beyond.

The Kyoto 2020 Commitment (KC2020) is a framework aimed at providing key actors and stakeholders concerned with landslide risk at all levels and sectors with the tools, information, platforms, technical expertise and incentives to promote landslide risk reduction on a global scale. It supports the implementation, follow-up and review of the Sendai Framework, the 2030 Agenda for Sustainable Development, the New Urban Agenda and the Paris Climate Agreement as it addresses the adverse effects of climate change.

KC2020 reaffirms the following resolution of the Sendai Partnerships, acknowledging that:

$\checkmark \quad$ Landslide disasters are caused by exposure to hazardous motions of soil and rock that threaten vulnerable human settlements 
in mountains, cities, on coasts, and islands.

$\checkmark \quad$ Climate change will intensify the risk of landslides in somelandslide prone areas through an increase in the frequency and/or magnitude of heavy rainfall, and shifts in the location and periodicity of heavy rainfall.

$\checkmark \quad$ Global warming will intensify the risk of landslides in permafrost area and glacial lake outburst floods through snow and ice melting.

$\checkmark \quad$ Developments in mountains and coastal areas, including construction of roads and railways and expansion of urban areas due to population shifts, increase exposure to hazards of landslides.

$\checkmark \quad$ Although they are not frequent, strong earthquakes have potential to trigger rapid and long runout landslides and liquefaction. Earthquake-induced coastal or submarine large-scale landslides or megaslides (with depths on the order of hundreds of meters to one thousand meters) in the ocean floor can trigger large tsunami waves. These hazardous motions of soil and water impacting on exposed and vulnerable population can result into very damaging effects.

$\checkmark \quad$ The combined effects of triggering factors, including rainfall, earthquakes, and volcanic eruptions, can lead to greater impacts through disastrous landslides such as lahars, debris flows, rock falls, and megaslides.

$\checkmark \quad$ Understanding landslide disaster risk requires a multi-hazard approach and a focus on social and institutional vulnerability. The study of social and institutional as well as physical vulnerability is needed to assess the extent and magnitude of landslide disasters and to guide formulation of effective policy responses.

$\checkmark \quad$ Human intervention can make a greater impact on exposure and vulnerability through, among other factors, land use and urban planning, building codes, risk assessments, early warning systems, legal and policy development, integrated research, insurance, and, above all, substantive educational and awareness-raising efforts by relevant stakeholders.

$\checkmark \quad$ The understanding of landslide disaster risk, including risk identification, vulnerability assessment, time prediction, and disaster assessment, using the most up-to-date and advanced knowledge, is a challenging task. The effectiveness of landslide disaster risk reduction measures depends on scientific and technological developments for understanding disaster risk (natural hazards or events and social vulnerability), political "buy-in", and on increased public awareness and education.

$\checkmark \quad$ At a higher level, social and financial investment is vital for understanding and reducing landslide disaster risk, in particular social and institutional vulnerability through coordination of policies, planning, research, capacity development, and the production of publications and tools that are accessible, available free of charge and are easy to use for everyone in both developing and developed countries.

We agree on the following priority actions of Kyoto 2020 Commitment for Global Promotion of Understanding and Reducing Landslide Disaster Risk in research and capacity building, coupled with social and financial investment:

Action 1 Promote the development of people-centered early warning technology for landslides with increased precision and reliable prediction both in time and location, especially in a changing climate context.

Action 2 Advance hazard and vulnerability mapping, including vulnerability and risk assessment with increased precision, as well as reliability as part of multi-hazard risk identification and management.

Action 3 Improve the technologies for monitoring, testing, analyzing, simulating, and effective early warning for landslides suitable for specific regions considering natural, cultural and financial aspects.

Action 4 Apply the ISDR-ICL Landslide Interactive Teaching Tools for landslide risk reduction in landslide prone areas and improve them with feedbacks from users in developed and less developed countries.

Action 5 Promote open communication with local governments and society through integrated research, capacity building, knowledge transfer, awareness-raising, training, and educational activities, to enable societies and local communities to develop effective policies and strategies for reducing landslide disaster risk, to strengthen their capacities for preventing hazards from developing into major disasters, and to enhance the effectiveness and efficiency of relief programs.

Action 6 Investigate the effect of climate change on rainfall-induced landslides and promote the development of effective rainfall forecasting models to provide earlier warning and evacuation especially in developing countries

Action 7 Investigate the mechanism and dynamics of submarine landslides during earthquakes that may cause or enhance tsunamis, as well as develop and upgrade its hazard assessment and mitigation measures

Action 8 Promote geotechnical studies of catastrophic megaslides and develop their prediction and hazard assessment. 
Action 9 Foster new initiatives to study research frontiers in understanding and reducing landslide disaster risk by promoting joint efforts by researchers, policy makers and funding agencies.

Action 10 Facilitate and encourage monitoring, reporting on, and assessing progress made, through the organization of progress report meetings at the regional and national level, to take place in respective countries, in order to show delivery and performance on progress made towards achieving the Kyoto 2020 commitment priority actions No.1-9. Participating parties and relevant stakeholders reporting on deliveries and achievements at these meetings are invited to report on this progress in the monthly full color journal "Landslides" so as to allow viewing progress in addressing landslide risk reduction. They are also encouraged to cooperate, as feasible and appropriate, with countries, the United Nations family, regional organizations, and all other partners and stakeholders concerned with landslide risk in their contribution to the Sendai Monitor System and the Voluntary National Reviews, and in their reporting on relevant key SDGs, notably on resilient and sustainable cities and climate action and on the Paris Agreement follow-up.

We submit that the above priority actions contribute to the four priority areas of the Sendai Framework and to the achievement of its seven global targets, in line with the "Words into Action” guidelines for Sendai Framework implementation, as well as of the SDG related targets. These actions also support landslide risk actors involved in building urban resilience so as to achieve coherence with the New Urban Agenda. Furthermore, they contribute to the discussion within the Global Platforms for Disaster Risk Reduction. Finally, they support the implementation of the Strategic Framework 2016-2021 of the United Nations Office for Disaster Risk Reduction (UNISDR).

We consider KC2020 as a framework to enhance cooperation in landslide risk reduction internationally, but also as a platform aimed at providing support to regional, national and local efforts, triggering exchanges on good practices and twinning and building the capacity of institutions and professionals at the national and local levels.

Commitments by all participating parties are periodically reviewed and updated at the Triennial World Landslide Forum in which parties of KC2020 are called upon to participate.

Fundamental Coordinating Commitments by the International Consortium on Landslides (ICL) and the Global Promotion Committee of the International Programme on Landslides (IPL) and others providing the common platform for the Kyoto 2020 Commitment include the following:

1. The Triennial Conference "World Landslide Forum" will be organized and the progress of Kyoto 2020 Commitment by all participating parties will be reported and examined for further development.

2. Landslides: Journal of International Consortium on Landslides will continue to be published monthly in full color and distributed to all participating parties.

3. Contribution fee and full color printing fee will continue to be waived to promote contribution from less developed countries and young researchers.

4. ICL provides that all parties of the Kyoto 2020 Commitment have the right to submit and publish news and reports of their activities in the "Landslides" journal. All parties will receive the digital access rights (tokens) to all issues of the journal (2002-present).

5. ICL will publish and update Landslide Dynamics: Landslide Interactive Teaching Tools (LITT) as a core activity for public education at each Forum. In early 2018, the first LITT (Vol.1 Fundamentals, Mapping and Monitoring, Vol.2 Testing, Risk Management and Country Practices) have been edited and published including PPT for lessons and PDF for reference in digital 
format.

6. ICL and the Global Promotion Committee of the International Programme on Landslides (GPC/IPL) will organize the annual IPL symposium and publish a series of books with ISBN numbers together with Research, Administrative and Strategic Review meetings at relevant venues such as UNESCO or elsewhere including the biennial Global Platform for Disaster Risk Reduction.

7. Other commitments by ICL and IPL groups will include:

$\checkmark \quad$ Landslide experts are called upon to gain trust and confidence from the local authorities and the communities facing the risk of landslides in order to effectively communicate the risk and urge local actions to help reduce the risk. Thus, ICL and IPL groups will promote a good dialogue at local levels throughout the activities of the Kyoto 2020 Commitment.

$\checkmark \quad$ To promote cooperation between policy makers, national government authorities working on landslide risk reduction and landslide scientists and engineers, a joint round table discussion between ICL members and high-level Ministerial members will be organized at each triennial Forum.

$\checkmark \quad$ Community safeguard policy for the countries/areas which are affected by rain-induced rapid and long-travel landslides, earthquake-induced megaslides as well as coastal and submarine landslides will be examined in specific sessions at each Forum.

$\checkmark \quad$ To identify, whenever possible and appropriate, focal points at the national/regional level in as many countries/regions as possible for engagement with the Kyoto 2020 Commitment and for ensuring contact and coordination with the Secretariat.

We are conscious that KC2020 will build and capitalize on the work and achievements of ICL and IPL notably the 2006 Tokyo Action Plan, the 2015 Sendai Partnerships and the outcomes of the World Landslide Fora.

We are committed to working together with Member States of the UN system, the UN family, regional organizations, and all other partners and stakeholders concerned with landslide risk, including civil society, academic, scientific and research entities, business, professional associates and private sector financial institutions, and the media.

We firmly believe that sustained cooperation and exchange between countries at a governmental level is needed if we are to promote in a sustainable way landslide risk reduction for resilience. Therefore, the timeliness and opportunity of having in place a platform or a mechanism at an intergovernmental level which would work to advise, strengthen and support decisions and initiatives on landslide risk reduction must be considered. This mechanism will enhance synergetic and concerted efforts not only among governmental entities but also between them and other sectors including the private sector and the civil society. We call upon stakeholders concerned to consider developing an Intergovernmental Panel on Landslide Risk Reduction in the framework of KC2020 within the International Programme on Landslides (IPL) so as to raise the level of interest in this area and maintain it through support to a long term global alliance that will continue to 2025, 2030 and beyond. The Panel will help mobilize strong political interest and commitment of the international community as well as further scientific knowledge and technological knowhow. It will advise on translating the objectives of ICL into meaningful programmes at the country level. The functions, form, governance and operation of the Panel will hopefully defined by relevant intergovernmental bodies.

\section{A Call for joining the Commitment}

Competent global, regional, national, local institutions and entities participating in the Fifth World Landslide Forum are invited to support this initiative by joining and signing this Commitment through participation in clearly defined commitments for understanding and reducing landslide disaster risk. The potential parties are requested to make contact with the Secretariat of the host organization. Furthermore, ICL and competent national, regional and international institutions are encouraged to enter into bilateral arrangements including through a dedicated Agreement of Cooperation which will provide a framework of cooperation and facilitate collaboration in areas of common interest and which enable both parties to mutually benefit and develop their cooperation, 
for the benefit of landslide hazard-prone communities in the country concerned and worldwide.

\section{Host Organization and Secretariat}

The International Consortium on Landslides (ICL) hosts the Kyoto 2020 Commitment as a voluntary commitment to the ISDR-ICL Sendai Partnerships 2015-2025, the Sendai Framework for Disaster Risk Reduction 2015-2030 and the 2030 Agenda Sustainable Development Goals. The ICL Secretariat in Kyoto, Japan, serves as the Secretariat of the Kyoto 2020 Commitment.

Signatories:

Signature

Name

Position

Organization

Date

Call for support to WLF5 2020 and Kyoto 2020 Commitment In 2018, ICL has created the new category, News/Kyoto Commitment, in the monthly full color journal Landslides: Journal of the International Consortium on Landslides (Sassa 2018b, d). It is a newsletter and a common platform for the $\mathrm{KC2O} 2 \mathrm{O}$. All people working in the field of landslides can contribute their latest research results and technological developments in the categories of original papers including review papers, recent landslides, and technical notes including case studies. ICL distributes the hard copy/the digital copy to all $\mathrm{KC}_{2020}$ partners. We can share all information or our activities and the announcement of meetings, schools, and field investigation to a larger community.

The $\mathrm{KC} 2020$ is a living platform. The priority actions and participation of partners are reviewed and updated at each triennial World Landslide Forum. If it will be agreed, it will be updated and extended. On the other hand, if it will be agreed not to continue, it will be terminated at any forum. There is no predecided period for this activity.

ICL calls its three types of ICL members and ICL supporting organizations to participate as partners of the $\mathrm{KC} 2020$ and sponsors of WLF5 to support the participation of researchers/engineers/policy makers from developing countries. Potential sponsors are requested to fill the preliminary registration form of WLF5. The WLF5 secretariat will contact the potential sponsors directly; http://wlf5.iplhq.org/preliminary-registration/.

\section{Acknowledgements}

The author extends his acknowledgement to all ICL members and ICL supporting members as well as other cooperating individuals for the organization of the WLF5. Thanks to those efforts, over 300 invited speakers have accepted to talk in the WLF5 in Kyoto, Japan. Those names, offices, and tentative titles of their talk are listed in the News/Kyoto Commitment in this issue. All coordinators of the WLF5 sessions and all accepted invited speakers are very much appreciated for the success of the WLF5.

\section{ANNEX}

The National Kyoto International Conference Center (KICC) was established in 1966 by the Government of Japan through design competition to host international conferences in Kyoto, Japan. The design by Yukio Otani was selected among 195 proposals. The Kyoto Protocol was adopted in the 3 rd Conference of the parties to the United Nations Framework Convention on Climate Change $\left(\mathrm{COP}_{3}\right)$ at this venue in 1997; the 3rd World Water Forum was organized at this venue in 2003.

The 2018 ICL-IPL Kyoto Conference including the WLF5 organizing committee meeting was held at the KICC and also in the Disaster Prevention Research Institute, Kyoto University, Kyoto, Japan, on 1-4 December 2018 (Fig. 1). In the opening session of the WLF5 organizing committee meeting, Ms. Mami Mizutori, Special Representative of the UN Secretary-General (SRSG) for Disaster Risk Reduction and Head of UNISDR, gave her message "SRSG Statement for the International Consortium Conference, Kyoto, Japan." Prof. Taikan Oki, Senior Vice-Rector of the United Nations University/United Nations Assistant Secretary, Ms. Setsuko Saya, Director of the International Cooperation Division, Disaster Management Bureau, Cabinet Office, Government of Japan, Dr. 
Soichiro Yasukawa, Coordinator for Disaster Risk Reduction and Resilience Section on Earth Sciences and Geo-hazards Risk Reduction, UNESCO, extended greetings to the participants. From WLF host organizations, Prof. Kaoru Takara from Japan Society for Natural Disaster Science (JSNDS) as well as Kyoto University, Prof. Daisuke Higaki from Japan Landslide Society, and Prof. Ryosuke Uzuoka from the Japanese Geotechnical Society extended their welcome greetings.

Qunli Han, Chair of GPC/IPL and Executive Director of IRDR (Integrated Research on Disaster Risk), chaired the GPC/IPL session. Matjaž Mikos (ICL Vice President and Forum Chair of WLF4), Dwikorita Karnawatai (ICL Vice President for Asia), Nicola Casagli (ICL Vice President for Europe), Binod Tiwari (ICL Vice President for America), Kaoru Takara (Executive Director of ICL), and Kyoji Sassa (Treasurer and Secretary General of ICL) chaired the Board of Representative (BOR/ ICL) meeting and other sessions. In this conference, the establishment of ICL Italian Network (ICL-Italy) and ICL Japanese network (ICL-Japan) (Sassa and Konagai 2018) to promote the planned Kyoto 2020 Commitment was approved at the presence of three representatives from the Government of Japan: Masaru Kunitomo, Director for Sabo (Erosion Control) Planning Coordination, Sabo Planning Division, Sabo Department, Ministry of
Land, Infrastructure, Transport and Tourism (MLIT), Yamato Tanaka, Deputy Director, Office for Disaster Reduction Research, Earthquake and Disaster-Reduction Research Division, Ministry of Education, Culture, Sports, Science and Technology (MEXT), Government of Japan, and Noriko Ishitobi, Deputy Director, Conservation Division, Forestry Agency, Ministry of Agriculture, Forestry and Fisheries (MAFF). Participants from 4 ICL members in China have proposed the establishment of ICL Chinese network, and participants from 3 ICL members in India have proposed the establishment of ICL Indian network. Both proposals were welcomed by BOR/ICL. The proposals will be examined in the 2019 ICL-IPL Conference.

Events on landslide-induced tsunamis

Fifth of November is "World Tsunami Awareness Day (WTAD)." Activities related to landslide-induced tsunamis are planned during the WLF5.

1. Session 1.3 landslide-induced tsunamis will be organized on 4 and 5 November 2020.

2. A symposium and panel discussion on landslide-induced tsunamis is under examination to be hosted on 5 November 2020 for the WLF5 participants and other tsunamirelated people.
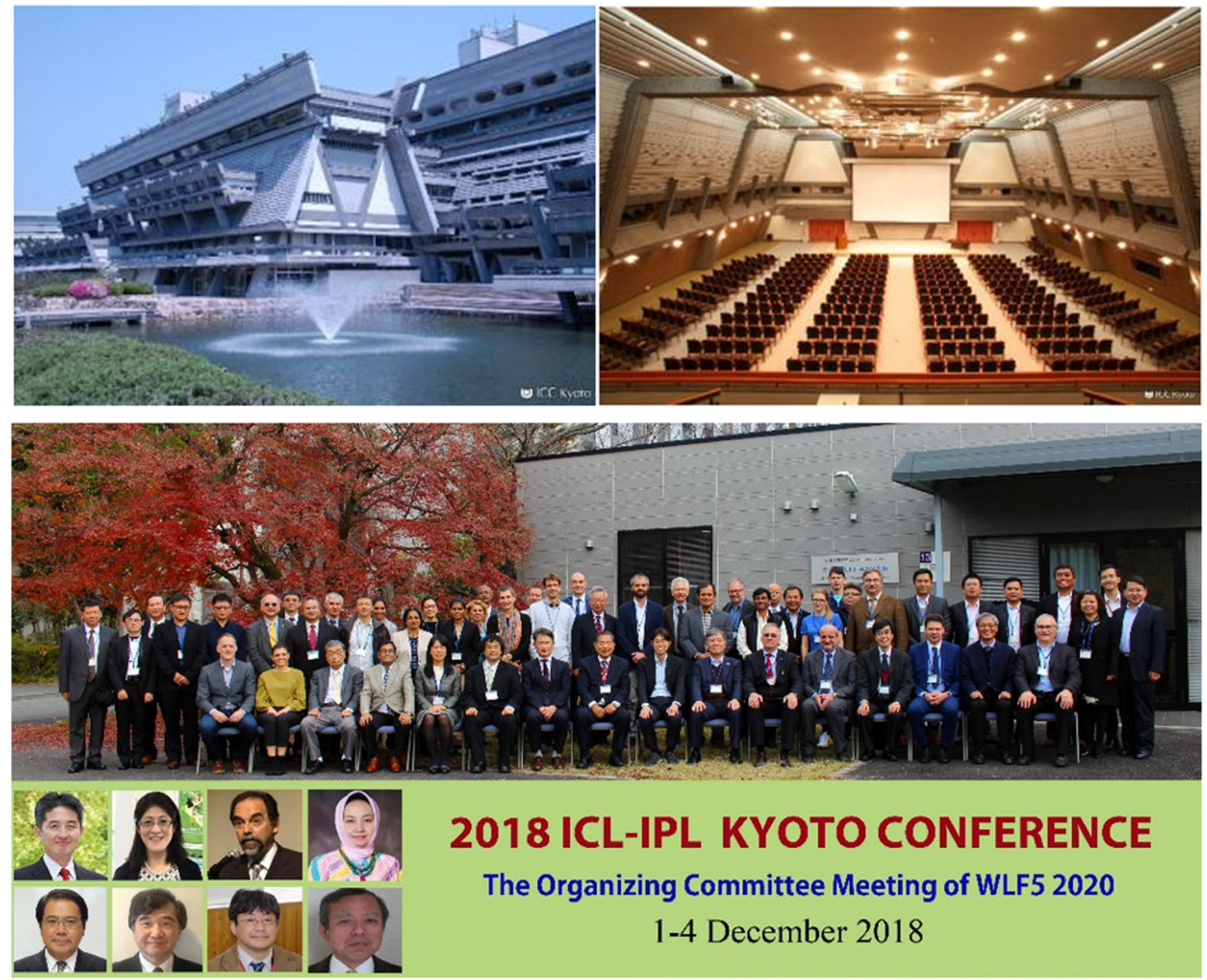

2018 ICL-IPL KYOTO CONFERENCE

The Organizing Committee Meeting of WLF5 2020

1-4 December 2018

Fig. 1 Photos of the KICC building and room "A" where the high-level panel discussion for the Kyoto 2020 Commitment is planned (top). A group photo of the 2018 ICLIPL Kyoto Conference in front of the UNESCO/KU/ICL UNITWIN Cooperation Programme Headquarters (bottom) 
3. The ICL-IPL inter-governmental panel on landslideinduced tsunamis, floods, and flows.

Policy makers from governments and experts from ICL and the Global Promotion Committee of the International Programme on Landslides (GPC/IPL) involved in landslide-induced tsunamis (e.g., due to coastal and submarine landslides), landslide-induced floods (e.g., 1963 Vajont Dam type and lake outburst type), and landslideinduced flows (e.g., debris flows, mud flows, pyroclastic flows) may create a joint panel.

4. Post-forum field trip to the Unzen-Mayuyama mega-slide and the landslide-induced tsunamis.
An earthquake-triggered mega-slide (volume, $3.4 \times$ $10^{8} \mathrm{~m}^{3}$; maximum depth, $400 \mathrm{~m}$ ) in Mayuyama of Unzen Volcano (Sassa et al. 2014) and the landslide mass which entered into Ariake Sea caused a big tsunami and affected Kumamoto prefecture and Amakusa Island. The total death toll was 15,153. It is considered as the world's largest landslide-induced tsunami disaster. It was published in Sassa et al. (2016) and reported, including video, in the World Report on Landslide in IPL WEBPAGE <http:// iplhq.org/report/1792-unzen-landslide-and-tsunami-disaster/> (Fig. 2).
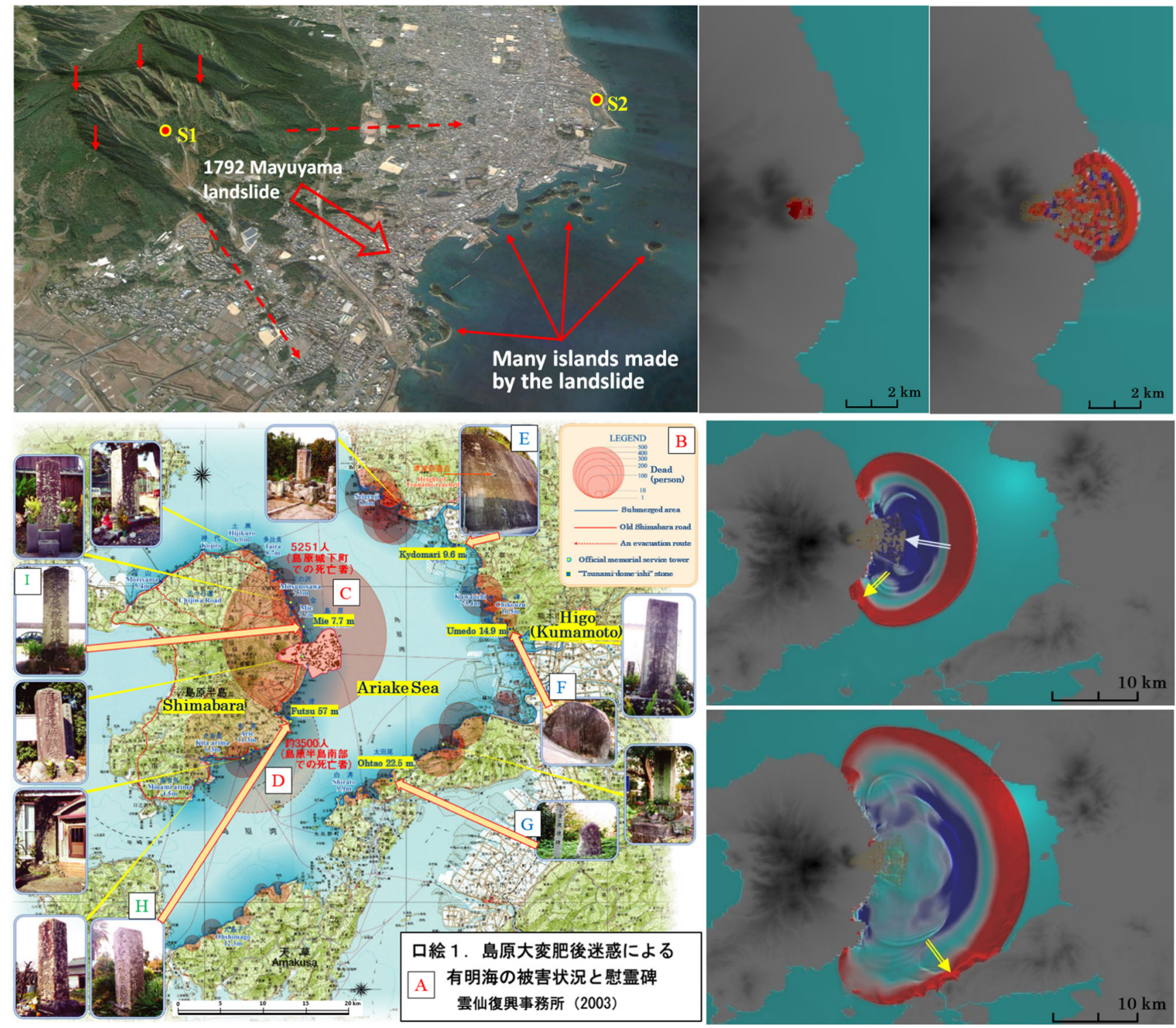

Fig. 2 Top left: Unzen-Mayuyama landslide. Bottom left: location and death by the landslide and tsunami disasters. Right: simulation result of the landslide and the landslide-induced tsunamis (Sassa et al. 2016) 


\section{References}

Sassa K (2017a) The Fifth World Landslide Forum -implementing and monitoring the ISDR-ICL Sendai Partnerships 2015-2025. Landslides 14(3):1283-1288

Sassa K (2017b) The 2017 Ljubljana Declaration on landslide risk reduction and the Kyoto2020 Commitment for global promotion of understanding and reducing landslide disaster risk. Landslides 14(4):1289-1296

Sassa K (2017c) The Fifth World Landslide Forum -implementing and monitoring the ISDR-ICL Sendai Partnerships 2015-2025- timeline of the WLF5 organization process and call for session proposals. Landslides 14(5):1857-1859

Sassa K (2017d) The ISDR-ICL Sendai Partnerships 2015-2025: background and content. In: Sassa K, Mikoš M, Yin Y (eds) Advancing culture of living with landslides. Springer, pp 3-21

Sassa K (2018a) Zero draft of the Kyoto 2020 Commitment for global promotion of understanding and reducing landslide disaster risk. Landslides 15(3):389-392

Sassa K (2018b) Monthly publication of landslides: journal of International Consortium on Landslides (ICL). Landslides 15(1):1-3

Sassa K (2018c) The Fifth World Landslide Forum -implementing and monitoring the ISDR-ICL Sendai Partnerships 2015-2025 - organization plan, themes and sessions. Landslides 15(3):617-620
Sassa K (2018d) ICL journal "Landslides" and the Kyoto 2020 Commitment. Landslides 15(9):1705-1712

Sassa K, Konagai K (2018) Establishment of ICL-Japan for the Kyoto 2020 Commitment. Landslides 15(11):2109-2111

Sassa K, Dang K, He B, Takara K, Inoue K, Nagai 0 (2014) A new high-stress undrained ring-shear apparatus and its application to the 1792 Unzen-Mayuyama megaslide in Japan. Landslide 11(5):827-842

Sassa K, Dang K, Yanagisawa H, He B (2016) A new landslide-induced tsunami simulation model and its application to the 1792 Unzen-Mayuyama landslide-and-tsunami disaster. Landslides 13(6):1405-1419

Sassa K et al (2019) Invited and accepted speakers of the Fifth World Landslide Forum in Kyoto, 2020. Landslides 16(2): in this issue

K. Sassa $(\varangle)$

IPL World Centre, ICL,

138-1 Tanaka-Asukai-cho, Sakyo-ku, Kyoto, 606-8226, Japan

Email: sassa@iclhq.org; kyoji.sassa@gmail.com 